\title{
EXPERIMENTAL INVESTIGATION OF OPTIMAL ED MACHINING PARAMETERS FOR Ti-6Al-4V BIOMATERIAL
}

\author{
UDC 621.9.011:669.295
}

\section{Amandeep Singh Bhui, Gurpreet Singh, Sarabjeet Singh Sidhu, Preetkanwal Singh Bains}

Department of Mechanical Engineering, Beant College of Engineering \& Technology, Punjab, India

\begin{abstract}
The present study investigates optimal parameters for machining of Ti-6Al$4 V$ using EDM with graphite electrode. Herein, another technique of modifying surface properties and enhancing machining rate using electrical discharge machining (EDM) was developed. In the present study, design of experiment (D.O.E) was developed using the Taguchi's orthogonal array to examine the effect of the input machining factors on the machining characteristics, and to forecast the optimized EDM parameters in terms of peak current, pulse-on time, pulse-off time and applied gap voltage. Each experiment was performed to obtain a hole of $1 \mathrm{~mm}$ depth on the workpiece. From the results, it is found that the discharge current has significant influence on material removal rate $(M R R)$ and surface roughness (SR) followed by other selected parameters, i.e. pulse-on time, pulse-off time. The MRR augmented steeply with the current and was recorded as maximum at 4 Amps. In-vitro bioactivity test was conducted in the simulated body fluid to examine bioactivity confirming a significant apatite growth on the surface treated with ED sparks. The surface and chemical alteration were analyzed by using Scanning Electron Microscopy (SEM) and X-Ray Diffraction (XRD) along with the identification of the substantially enhanced morphology for clinical success.
\end{abstract}

Key Words: Electrical Discharge Machining, Material Removal Rate, Surface Roughness, Bioactivity

\section{INTRODUCTION}

One of the most investigated modern machining processes in the recent decades is electric discharge machining (EDM). The conversion of electric into heat energy takes place in the gap between the electrode and the workpiece [1]. The EDM is widely used in

Received August 24, 2018 / Accepted November 01, 2018

Corresponding author: Gurpreet Singh

Department of Mechanical Engineering, Beant College of Engineering \& Technology, Gurdaspur-143521, Punjab, India

E-mail: singh.gurpreet191@gmail.com 
die making, aerospace and medical industries. During the spark generation, material erosion from both the electrodes takes place and at the end of machine cycle, constituents from both the dielectric and the tool electrodes get deposited on the material surface [2]. The EDM is found to be a potential candidate for producing surfaces with better surface topology and precision, compared to other machining methods [3].

Titanium alloys have wide applications in aerospace, medical domain (dental and orthopedics) subject to their competitive mechanical, anti-corrosive, and biocompatible properties. Ti-6Al-4V $(\alpha+\beta)$ phase alloy has been the most desirable metallic biomaterial for medical implants $[4,5]$. However, the presence of amino acids and proteins in the body fluids accelerates the corrosion process by releasing metallic ions which causes poor osseointegration and leads to cytotoxicity resulting in allergic reactions and, ultimately, to failure of the implant [6]. Although the formation of metallic ions is harmful, the use of Ti-6Al-4V alloy would continue due to its excellent properties for use in the human body. For this reason, improvement in surface properties of the alloy is required for prolonged metalbone-tissue adhesion.

The experiments were conducted on Ti grade-5 alloy by Verma et al. [7] using copper electrode in the die sinking EDM for optimum input parameters manifested to attain maximum MRR and minimum surface roughness. Micro-cracks and craters were observed under the SEM on the EDMed surface. Kumar et al. [8] put forward the investigation of MRR and surface finish of Ti-6Al-4V ELI with the EDM using current, pulse-on and voltage as input parameters. The current was concluded as the most significant factor for both MRR and surface roughness. Optimum parameters were 18 ampere, 40 volts and 100 $\mu$ s pulse-on that yielded maximum MRR and minimum SR. Peng et al. [9] investigated that ED machining of titanium alloy performed for a short duration resulted in the formation of nano-structured compounds on the surface while a bioactive nano-porous $\mathrm{TiO}_{2}$ layer was also observed at the same time. Lee et al. [10] studied the EDMed layer of Ti-6Al-4V alloy by varying pulse durations from $10 \mu$ s to $60 \mu \mathrm{s}$. The new surface thus produced had micro surface roughness and a nano-porous $\mathrm{TiO}_{2}$ layer. Increased adhesion, proliferation and differentiation of MG63 cells were observed. It was concluded by Prakash et al. [11] that EDM holds the potential for surface improvement and surface modification of Ti alloy in terms of forming oxides and carbides on the surface that inhibit bio-compatibility, improve surface hardness, corrosion resistance and the formation of a nano-porous layer.

Ayesta et al. [12] conducted a study project on EDM applications, effects of input factors on output responses by machining thin slots using electrical discharge machining. They concluded that peak current and pulse-on time were the dominant factors affecting machining time and the tool wear rate and machining time. Ristic et al. [13] presented their work on the selection of material for implants using 'Expert system'. In their study, they demonstrated a novel technique based on multiple criteria decision-making using fuzzy logic for appropriate selection of biomaterial. Similarly, while optimizing the metal removal rate and SR of EN31 tool steel in EDM machining by Das et al. [14], it was found that the discharge current was the most significant parameter for variations in the metal erosion rate. With increase in the value of discharge current and pulse-on-time, the metal erosion rate also increased during the machining process.

Mahajan et al. [15] reviewed the feasibility of various metallic biomaterials, i.e. titanium alloy, stainless steel, $\mathrm{Cr}$-Co alloys and their surface modification techniques for enhanced functionality. Torres et al. [16] conducted their experiments using copper electrode for better surface properties of machining and concluded that MRR was directly proportional to 
the current, i.e. the former enhanced with increase in discharge current due to rise in temperature of the workpiece. Furthermore, with increase in pulse time, the electrode wear decreased drastically, whereas surface roughness was greater at higher pulse-on time and higher current intensity.

$\mathrm{Ti}$ and its alloys especially Ti-6Al-4V alloy gained more attention in recent scenario, due to their superior biocompatibility and excellent mechanical properties, especially low Young's modulus, high fatigue performance, high corrosion resistance and low density as compared to other metallic biomaterials [17]. This study is dedicated to interpreting the influence of EDM process parameters on the machining rate and surface characterization of medical grade Titanium alloy. Furthermore, the in-vitro test was conducted on the machined province for examining biological behavior of the modified surfaces.

\section{MATERIAL AND METHOD}

\subsection{Materials used}

Titanium Grade 5 (Ti-6Al-4V) procured from Baoji Fuyuan Tong Industry and Trade Co. Ltd., China, was employed as the workpiece in the form of a rectangular block (size: $80 \mathrm{~mm} \times 80 \mathrm{~mm} \times 5 \mathrm{~mm}$ ) for conducting experimentation. An electrolytic graphite electrode with diameter of $900 \mu \mathrm{m}$ was preferred as a tool due to its better conductivity for the machining purpose. The chemical composition of Ti-6Al-4V used for the experimentation is shown in Table 1.

Table 1 Chemical Composition of Ti-6Al-4V

\begin{tabular}{ccccccccc}
\hline Element & $\mathrm{Fe}$ & $\mathrm{C}$ & $\mathrm{O}$ & $\mathrm{N}$ & $\mathrm{H}$ & $\mathrm{Al}$ & $\mathrm{V}$ & $\mathrm{Ti}$ \\
\hline$\%$ & 0.09 & 0.03 & 0.03 & 0.003 & 0.001 & 6.1 & 4.2 & Balance \\
\hline
\end{tabular}

\subsection{Method}

The design of experiment was generated using the Taguchi's $\mathrm{L}_{9}(4 \times 3)$ array by Minitab 17 software. Table 2 demonstrates the input machining factors, i.e. current, pulse-on time, pulse-off time, gap voltage, with their respective levels selected for the experimentation. The output parameters were analyzed with the condition 'larger-is-better' for material removal rate and surface finish. The units and levels of experimental factors, i.e. discharge current, pulse-on time, pulse-off time and voltage are shown in Table 2.

Table 2 Factors and their levels

\begin{tabular}{lcccc}
\hline Input Factors & Level 1 & Level 2 & Level 3 & Units \\
\hline Current (I) & 1 & 2 & 4 & $\mathrm{~A}$ \\
Pulse-on time (P-on) & 30 & 45 & 60 & $\mu \mathrm{s}$ \\
Pulse-off time (P-off) & 60 & 90 & 120 & $\mu \mathrm{s}$ \\
Voltage (V) & 30 & 40 & 50 & $\mathrm{~V}$ \\
\hline
\end{tabular}

\subsection{Experimental Procedure}

The experiments were performed on the die sinker type EDM Machine (make: OSCARMAX, Taiwan, Fig. 1) in negative polarity conditions (i.e., the work piece (-) and tool 
electrode (+)). During machining, the tool feed was set downward to the workpiece with the servo mechanism used by the EDM. Magnetic fixtures were used to hold the workpiece and the electrode during the process. For each trial, machining was carried out up to a depth of 1 $\mathrm{mm}$ on the workpiece surface and time for each experiment was noted down. Surface roughness was measured using the Mitutoyo SJ-400 surface roughness tester in terms of arithmetic average of absolute value $\mathrm{Ra}(\mu \mathrm{m})$. Each sample was measured diametrically from three locations on the machined surface and was averaged for further analysis. After the machining, surface roughness was checked using the Mitutoyo surface roughness tester.

In this experimentation, discharge current (I), pulse-on time (P-on), pulse-off time ( $\mathrm{P}$ off) and voltage $(\mathrm{V})$ were selected as input factors being the most common and influencing parameters. The response parameters selected were material removal rate $(\mathrm{mg} / \mathrm{min})$ and surface roughness $\left(R_{a}\right)$ in $\mu \mathrm{m}$.

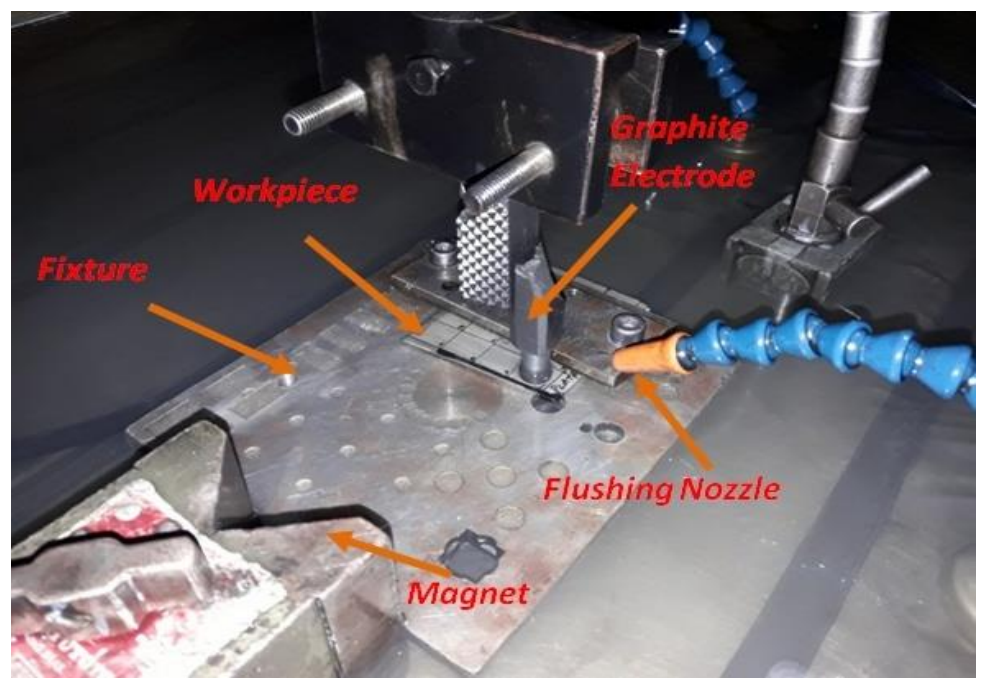

Fig. 1 Pictorial view of experimental set-up

Further, a bone-like apatite formation ability test was conducted to analyze bioactivity of the EDM-treated Ti-6Al-4V alloy. Disc type samples of $10 \mathrm{~mm} \times 5 \mathrm{~mm}$ were cut from EDM-treated Ti-6Al-4V alloy specimen using Wire-EDM. Then, the samples were immersed in $50 \mathrm{~mL}$ Ringer's solution in a hermetic beaker and kept under thermostatic conditions in a water bath at $37 \pm 1^{\circ} \mathrm{C}$ for 7 days, as per the procedure adopted elsewhere [18].

\section{RESULTS AND DISCUSSION}

MRR and surface roughness were calculated against the combination of selected input machining parameters. Digital weighing machine (Citizen, CY220), with reading up to three decimal places, was used to measure weight before and after machining for each sample; surface roughness was measured with the Mitutoyo surface roughness tester. The experimental design matrix and responses are shown below in Table 3. The responses tabulated in Table 3 are represented according to the Signal to Noise Ratio $(\mathrm{S} / \mathrm{N})$ 
methodology - a ratio of strength of signal to the magnitude of error. $\mathrm{S} / \mathrm{N}$ ratio depends on the type of responses measured such as a "higher-is-better" type given by equation below:

$$
\left(\frac{\mathrm{S}}{\mathrm{N}}\right)_{\mathrm{HB}}=-10 \log \left\{\frac{1}{\mathrm{R}} \sum_{\mathrm{i}=1}^{\mathrm{R}}\left(\frac{1}{\mathrm{y}_{\mathrm{i}}^{2}}\right)\right\}
$$

where $\mathrm{R}$ is the number of repetitions of responses; $\mathrm{y}_{\mathrm{i}}$ value of response at $i^{\text {th }}$ trial.

Table 3 Experimental design and responses

\begin{tabular}{|c|c|c|c|c|c|c|c|c|c|c|}
\hline \multirow{3}{*}{$\begin{array}{l}\text { Exp. } \\
\text { No. }\end{array}$} & \multirow{3}{*}{$\begin{array}{l}\text { Current } \\
\text { (A) }\end{array}$} & \multirow{3}{*}{$\begin{array}{l}\text { P-on } \\
(\mu \mathrm{s})\end{array}$} & \multirow{3}{*}{$\begin{array}{c}\text { P-off } \\
(\mu \mathrm{s})\end{array}$} & \multirow{3}{*}{$\begin{array}{l}\text { Voltage } \\
\text { (V) }\end{array}$} & \multicolumn{6}{|c|}{ Responses } \\
\hline & & & & & \multicolumn{3}{|c|}{ MRR (mg/min.) } & \multicolumn{3}{|c|}{$\mathrm{SR}(\mu \mathrm{m})$} \\
\hline & & & & & R1 & R2 & $\begin{array}{c}\text { S/N ratio } \\
(\mathrm{dB})\end{array}$ & R1 & R2 & $\begin{array}{c}\text { S/N ratio } \\
(\mathrm{dB})\end{array}$ \\
\hline 1 & 1 & 30 & 60 & 30 & 2.00 & 2.00 & 6.0206 & 0.073 & 0.080 & -22.35 \\
\hline 2 & 1 & 45 & 90 & 40 & 1.73 & 1.77 & 4.8591 & 0.106 & 0.050 & -23.88 \\
\hline 3 & 1 & 60 & 120 & 50 & 2.07 & 1.94 & 6.0286 & 0.103 & 0.103 & -19.74 \\
\hline 4 & 2 & 30 & 90 & 50 & 4.94 & 5.72 & 14.4647 & 0.176 & 0.210 & -14.39 \\
\hline 5 & 2 & 45 & 120 & 30 & 6.73 & 7.93 & 17.2147 & 0.593 & 0.499 & -5.352 \\
\hline 6 & 2 & 60 & 60 & 40 & 8.70 & 9.31 & 19.0747 & 0.116 & 0.086 & -20.20 \\
\hline 7 & 4 & 30 & 120 & 40 & 6.00 & 6.00 & 15.5630 & 0.560 & 0.426 & -6.385 \\
\hline 8 & 4 & 45 & 60 & 50 & 25.61 & 23.59 & 27.7967 & 0.123 & 0.120 & -18.31 \\
\hline 9 & 4 & 60 & 90 & 30 & 26.88 & 24.89 & 28.2417 & 1.140 & 1.156 & 1.198 \\
\hline
\end{tabular}

\subsection{Analysis of variance of $S / N$ ratio for $M R R$, and $S R$}

The responses were analyzed using statistical analysis of variance (ANOVA) of the $\mathrm{S} / \mathrm{N}$ ratio using the Taguchi's methodology presented in Table 4. For ANOVA the insignificant process parameters are pooled and the most significant process parameters are identified using p-value. In Table 4 the current is the most significant factor affecting MRR (\% contribution: 77.39 ) and SR (\% contribution: 46.17). The material removal capacity rises steeply with rise in the current and maximum at $4 \mathrm{~A}$. Thus, the precise productivity of the selected biomaterials can be enhanced at a high current value (i.e. 4 A) which simultaneously provides the desired surface morphology for requisite bioactivity. The optimum values identified for the desired output are selected from the main effect plot as shown in Fig. 2. Furthermore, one set of experiment is conducted on these optimum value results in MRR as $25.64 \mathrm{mg} / \mathrm{min}$ and SR measured as $16.13 \mu \mathrm{m}$.

Table 4 Analysis of variance for $\mathrm{S} / \mathrm{N}$ ratio of responses

\begin{tabular}{|c|c|c|c|c|c|c|c|c|c|}
\hline \multirow{2}{*}{ Factors } & \multirow{2}{*}{ DoF } & \multicolumn{2}{|c|}{ Sum of Squares } & \multicolumn{2}{|c|}{ Variance } & \multicolumn{2}{|c|}{ p-Value } & \multicolumn{2}{|c|}{$\%$ contribution } \\
\hline & & MRR & SR & MRR & SR & MRR & SR & MRR & SR \\
\hline Current & 2 & 507.94 & 277.4 & 253.97 & 138.7 & $0.048 *$ & $0.028 *$ & 77.39 & 46.17 \\
\hline Pulse-on & 2 & 55.81 & \# & 27.91 & \# & 0.315 & \# & 4.83 & \# \\
\hline Pulse-off & 2 & 33.72 & 171.3 & 16.86 & 85.66 & 0.432 & $0.044 *$ & 1.29 & 27.99 \\
\hline Voltage & 2 & $\#$ & 127.2 & \# & 63.22 & \# & 0.058 & \# & 20.44 \\
\hline Error & & 25.67 & 7.87 & 12.83 & 3.93 & & & & \\
\hline Total & & 623.15 & 583.5 & & & & & & \\
\hline
\end{tabular}



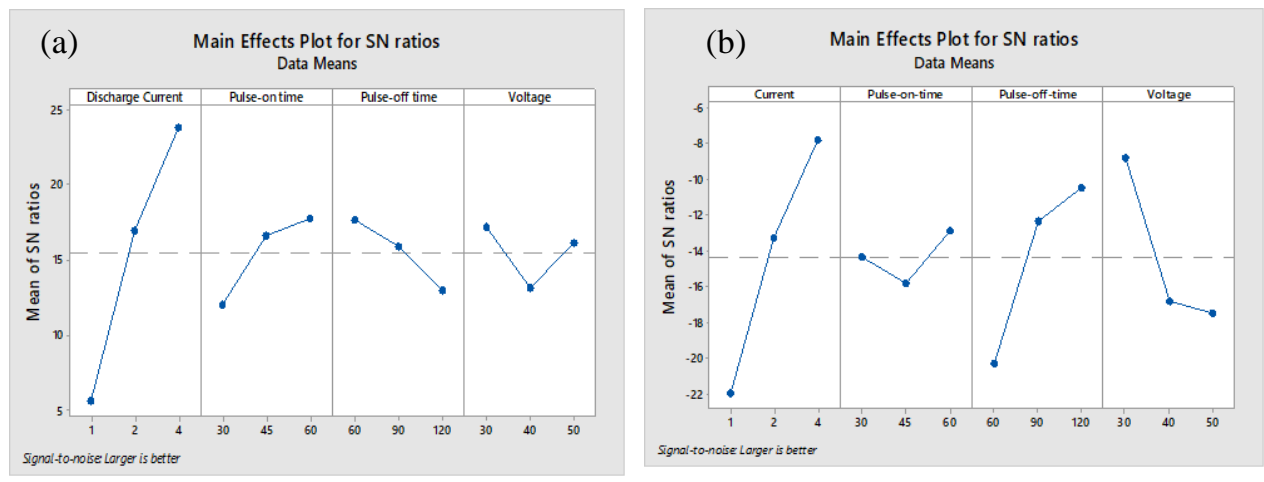

Fig. 2 Main effects plot for S/N ratio (a) Material removal rate (b) Surface roughness

The EDMed surface obtained at optimal values of process parameters was subjected to surface analysis in terms of surface topography, chemical composition to examine the machined surface and in-vitro bioactivity analysis.

The morphology of EDMed sample was investigated using the SEM (JSM-6610 LV Joel, Japan). The SEM (Fig. 3) reveals the formation of craters (pores) and material deposition. Further, it is affirmed that the formation of porous structure represents favorable surface conditions for the cell growth.

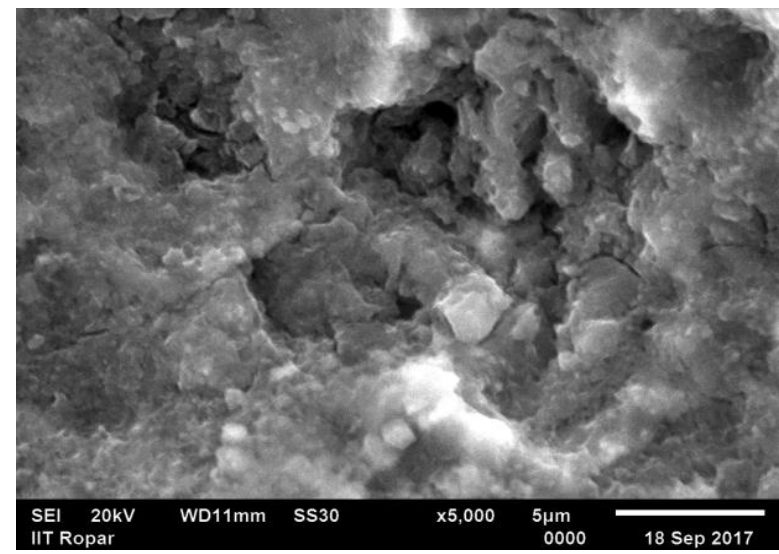

Fig. 3 SEM of EDMed surface representing the porous structure at $\mathrm{I}=4 \mathrm{~A} ; \mathrm{P}$-off $=120 \mu \mathrm{s} ; \mathrm{V}=30 \mathrm{~V}$

It was depicted in the previous study that the EDM spark energy altered the surface morphology and chemical composition thus supporting cell viability. The X-ray diffractometer (XRD) pattern of the EDMed surface is shown in Fig. 4. The XRD analysis results confirm the formation and deposition of various inter-metallic compounds and carbides as well as silicides on the EDMed surface. The formation of silicides and carbide demonstrated high corrosion resistance and contribute to enhanced bioactivity [19]. 


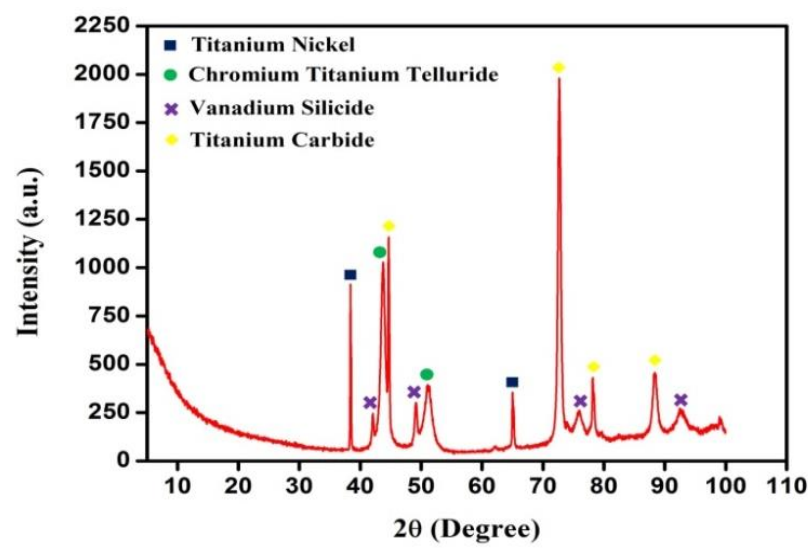

Fig. 4 XRD spectra of EDMed surface showing formation of new compounds

\subsection{In-vitro bioactivity analysis}

The capacity of apatite formation in simulated body solution (clean ringer's solution with $\mathrm{pH}$ value 7.2) has been widely used to assess bioactivity of biomaterials. The bioactivity of the EDMed surface of Ti-6Al-4V alloy was evaluated by the apatite growth level. The immersion of specimen in the Ringer's solution in particular environmental conditions allows deposition of calcium phosphates on the surface. Fig. 5 shows the growth of apatite layer on the EDMtreated substrate in a hermetic beaker and kept under thermostatic conditions in a water bath at $37 \pm 1{ }^{\circ} \mathrm{C}$ for 7 days. The SEM micrograph showed the formation of hydroxyapatite (HAp: a constituent of natural bone) content on the EDM-treated surface, which indicates the apatiteinducing ability, as can be seen in Fig. 5. The associated EDS spectrum confirms the presence of $\mathrm{Ca}$ and $\mathrm{O}$ elements on the EDM-treated Ti-6Al-4V alloy surface, which conferred the formation of apatite layer, as can be seen in Fig. 6.

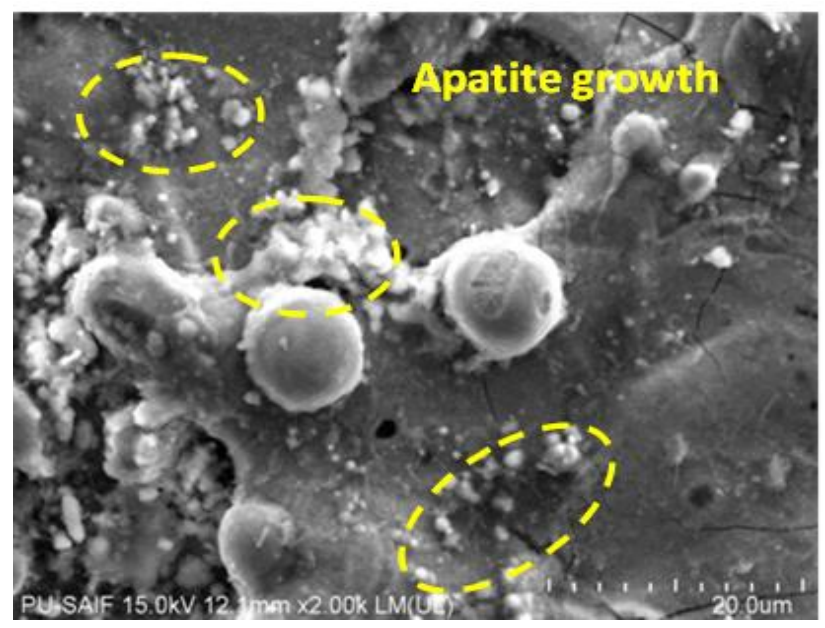

Fig. 5 SEM showing formation of apatite growth 


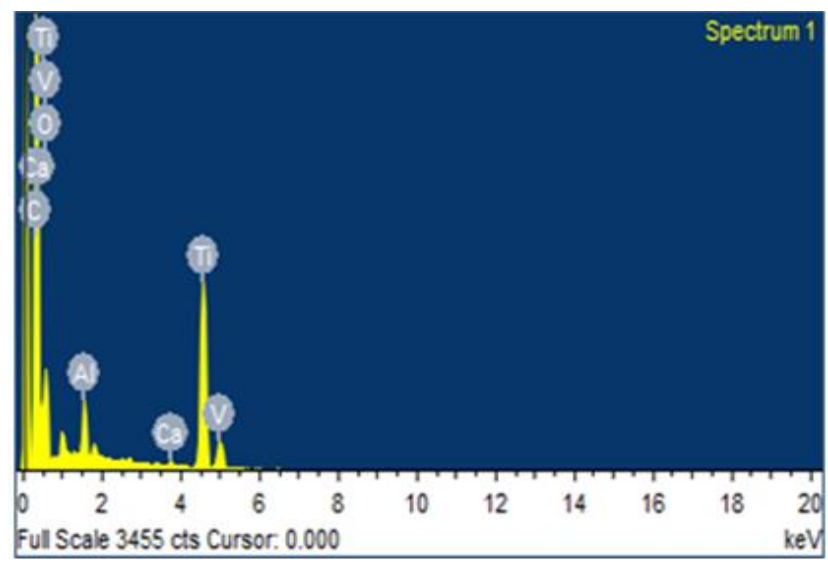

Fig. 6 EDS spectrum showing elements on EDM-treated Ti-6Al-4V alloy

\section{CONCLUSIONS}

The surface of the Ti-6Al-4V alloy specimen was processed by the EDM at negative polarity to explore machining performance and biological responses. The following observations are made:

- The material erosion rate is directly proportional to the current, whereas bioactive morphology is obtained at optimal combination of the process parameters such as $\mathrm{I}=4 \mathrm{~A} ; \mathrm{P}-\mathrm{off}=120 \mu \mathrm{s} ; \mathrm{V}=30 \mathrm{~V}$.

- The material removal capacity increased significantly with rise in the current and was witnessed as maximum at $4 \mathrm{~A}$. The same output parameter, on the contrary, declined with decrease in pulse-off duration.

- The EDMed samples at the optimal spark energy (i.e. $I=4 \mathrm{~A} ; \mathrm{P}$-off $=120 \mu \mathrm{s}$; $\mathrm{V}=30 \mathrm{~V}$ ) resulted in the development of pores and evolution of carbides and silicides on the machined substrate.

- Peak current (I), pulse-off duration and voltage have been the significant deciding factors while analyzing the SR as response.

- The apatite-inducing capability of the EDMed surface has been enhanced in the machined surface, thus bestowing excellent bioactivity.

\section{REFERENCES}

1. Bains, P.S., Sidhu, S.S., Payal, H.S., 2016, Study of Magnetic Field Assisted ED Machining of Metal Matrix Composites, Materials and Manufacturing Processes, 31(14), pp.1889-1894.

2. Mahajan, A., Sidhu, S.S., 2018, Enhancing biocompatibility of $\mathrm{Co}-\mathrm{Cr}$ alloy implants via electrical discharge process, Materials Technology, 33(8), pp. 531-534.

3. Bains, P.S., Sidhu, S.S., Payal, H.S., Kaur, S., 2018, Magnetic Field Influence on Surface Modifications in Powder Mixed EDM, Silicon, doi:10.1007/s12633-018-9907-z.

4. Singh, P., Pungotra, H., Kalsi, N.S., 2017, On the characteristic of titanium alloys for the aircraft applications, Materials today: proceedings, 4(8), pp. 8971-8982. 
5. Uwais, Z.A., Hussein, M.A., Samad, M.A., Al-Aqeeli, N., 2017, Surface modification of metallic biomaterials for better tribological properties: A review, Arabian Journal of Science and Engineering, 42(11), pp. 4493-4512.

6. Manam, N.S., Harun, W.S.W., Shri, D.N.A., Ghani, S.A.C., Kurniawan, T., Ismail, M.H., Ibrahim, M.H.I., 2017, Study of corrosion in biocompatible metals for implants: A review, Journal of Alloys and Compounds, 701, pp. 698-715.

7. Verma, V., Sahu, R., 2017, Process parameter optimization of die-sinking EDM on Titanium grade-V alloy (Ti6Al4V) using full factorial design approach, Materials today: proceedings, 4(2), pp. 1893-1899.

8. Kumar, R., Roy, S., Gunjan, P., Sahoo, A., Sarkar, D.D., Das, R.K., 2018, Analysis of MRR and Surface Roughness in Machining Ti-6Al-4V ELI Titanium Alloy Using EDM Process, Procedia Manufacturing, 20, pp. 358-364.

9. Peng, P.W., Ou, K.L., Lin, H.C., Pan, Y.N., Wang, C.H., 2010, Effect of electrical discharging on formation of nanoporous biocompatible layer on titanium, Journal of Alloys and Compounds, 492(1-2), pp. 625-630.

10. Lee, W.F., Yang, T.S., Wu, Y.C., Peng, P.W., 2013, Nanoporous Biocompatible Layer on Ti6Al4V Alloys Enhanced Osteoblast-like Cell Response, Journal of Experimental and Clinical Medicine, 5(3), pp. 92-96.

11. Prakash, C., Kansal, H.K., Pabla, B.S., Puri, S., Aggarwal, A., 2015, Electric discharge machining-A potential choice for surface modification of metallic implants for orthopedic applications: A review, Proceedings of the Institution of Mechanical Engineers, Part B: Journal of Engineering Manufacture, 230(2), pp. 331-353.

12. Ayesta, I., Izquierdo, B., Sanchez, J.A., Ramos, J.M., Plaza, S., Pombo, I., Ortege, N., Bravo, H., Fradejas, R., Zamakona, I., 2013, Influence of EDM parameters on slot machining in C1023 aeronautical alloy, Procedia CIRP, 6, pp. 129-134.

13. Ristic, M., Manic, M., Misic, D., Kosanovic, M., Mitkovic, M., 2017, Implant material selection using expert system, Facta Universitatis-Series Mechanical Engineering, 15(1), pp. 133-144.

14. Das, M.K., Kumar, K., Barman, T.K., Sahoo, P., 2014, Application of artificial bee colony algorithm for optimization of MRR and surface roughness in EDM of EN31 tool steel, Procedia Material Science, 6, pp. 741-751.

15. Mahajan, A., Sidhu, S.S., 2017, Surface modification of metallic biomaterials for enhanced functionality: A Review, Materials Technology, 33(2), pp. 93-105.

16. Torres, A., Luis, C.J., Puertas, I., 2017, EDM machinability and surface roughness analysis of TiB2 using copper electrodes, Journal of Alloys and Compounds, 690, pp. 337-347.

17. Harcuba, P., Bacakova, L., Strasky, J., Bacakova, M., Novotna, K., Janecek, M., 2012, Surface treatment by electric discharge machining of Ti-6Al-4V alloy for potential application in orthopaedics, Journal of the mechanical behaviour of biomedical materials, 7, pp. 96-105.

18. Prakash, C., Singh, S., Verma, K., Sidhu, S.S., Singh, S., 2018, Synthesis and characterization of Mg-Zn-MnHA composite by spark plasma sintering process for orthopedic applications, Vacuum, 155, pp. 578-584

19. Jenko, M., Gorensek, M., Godec, M., Hodnik, M., Batic, B.S., Donik, C., Grant, J.T., Dolinar, D., 2018, Surface chemistry and microstructure of metallic biomaterials for hip and knee endoprostheses, Applied Surface Science, 427, pp. 584-593. 